Family Medicine and Community Health

\title{
Exploring the association of social determinants of health and clinical quality measures and performance in HRSA-funded health centres
}

\author{
Michael Topmiller, ${ }^{1}$ Jessica McCann, ${ }^{1}$ Jennifer Rankin, ${ }^{1}$ Hank Hoang, ${ }^{2}$ \\ Joshua Bolton, ${ }^{2}$ Alek Sripipatana ${ }^{2}$
}

To cite: Topmiller M, McCann J, Rankin J, et al. Exploring the association of social determinants of health and clinical quality measures and performance in HRSA-funded health centres. Fam Med Com Health 2021;9:e000853. doi:10.1136/fmch-2020-000853
Check for updates

(C) Author(s) (or their employer(s)) 2021. Re-use permitted under CC BY-NC. No commercial re-use. See rights and permissions. Published by BMJ.

${ }^{1}$ HealthLandscape, American Academy of Family Physicians, Leawood, Kansas, USA

${ }^{2}$ Bureau of Primary Health Care, Health Resources and Services Administration, Rockville, Maryland, USA

Correspondence to Dr Michael Topmiller; mtopmiller@aafp.org

\section{ABSTRACT}

Objective This paper explores the impact of service arealevel social deprivation on health centre clinical quality measures.

Design Cross-sectional data analysis of Health Resources and Services Administration (HRSA)-funded health centres. We created a weighted service area social deprivation score for HRSA-funded health centres as a proxy measure for social determinants of health, and then explored adjusted and unadjusted clinical quality measures by weighted service area Social Deprivation Index quartiles for health centres.

Settings HRSA-funded health centres in the USA. Participants Our analysis included a subset of 1161 HRSA-funded health centres serving more than 22 million mostly low-income patients across the country. Results Higher levels of social deprivation are associated with statistically significant poorer outcomes for all clinical quality outcome measures (both unadjusted and adjusted), including rates of blood pressure control, uncontrolled diabetes and low birth weight. The adjusted and unadjusted results are mixed for clinical quality process measures as higher levels of social deprivation are associated with better quality for some measures including cervical cancer screening and child immunisation status but worse quality for other such as colorectal cancer screening and early entry into prenatal care.

Conclusions This research highlights the importance of incorporating community characteristics when evaluating clinical outcomes. We also present an innovative method for capturing health centre service area-level social deprivation and exploring its relationship to health centre clinical quality measures.

\section{INTRODUCTION}

It is well established that social determinants influence health outcomes. ${ }^{1}$ While many definitions exist, WHO defines social determinants of health as the conditions in which we are born, grow, live, work and age. ${ }^{2}$ Research shows that social determinants, such as poverty, education and housing, have more influence on health than genes, health behaviours and medical care. ${ }^{3}$

\section{Key points}

- Given the impact of place on health, this research presents a novel methodology for incorporating service area-level data on social deprivation into analysis of clinical quality measures for health centres. Health centres with higher rates of service area social deprivation perform significantly better on some clinical quality process measures such as cervical cancer screening and use of appropriate medications for asthma, even after adjusting for health centre patient characteristics. Higher levels of service area social deprivation are associated with significantly worse clinical quality outcomes (blood pressure control, poor haemoglobin A1c control, low birth weight).

- Question: What is the impact of service area social deprivation on health centre clinical quality?

- Finding: The impact of service area social deprivation is mixed for health centre clinical process measures. It is clear that higher levels of service area social deprivation are associated with worse clinical quality outcomes.

- Meaning: It is necessary to include service arealevel social determinants when evaluating health centre clinical quality performance.

Integrating community-level data with clinical data is an approach for identifying and addressing relevant social determinants and can lead to improved health outcomes. ${ }^{4}$ Technical advances in recent years allow for providers to assess community-level data as they pertain to individual patients in real time. Bazemore et al assigned geographical identifiers to a patient's address and linked those identifiers to existing non-clinical data sets on the built environment, economic conditions, demographics and resources. These small area data sets, referred to as 'Community Vital Signs,' were then uploaded into the patient's electronic health records (EHR).$^{5}$ Liaw et al assigned patient addresses to census 
tracts, linked each census tract with a Social Deprivation Index (SDI) and other data on poverty and education, then identified patients living in 'cold spots.' Further, they found that living in a 'cold spot' is associated with poor clinical outcomes and lower quality of care. ${ }^{6}$

Combining multiple neighborhood-level determinants into a single measure of deprivation, as in Phillips et al, allows for multidimensional vulnerability assessment and resource targeting. By using a deprivation index, practitioners can easily view a community's 'vital signs' and provide context-informed care, where care plans are tailored based on community characteristics. ${ }^{7}$ While there is no consensus on which community characteristics are most important in measuring social deprivation and predicting health outcomes, researchers have developed and tested various models. Despite these indices being developed at various geographies, including tract ${ }^{8}$ and county, ${ }^{9}$ and being composed of different indicators, they all illustrate that high levels of deprivation are associated with poor health outcomes and the need to look beyond patient characteristics when exploring clinical quality.

Given the influence of community characteristics on health outcomes, community-level social deprivation is of particularly interest to federally funded health centres. The Health Resources and Services Administration's (HRSA) Health centre Programme serves the most vulnerable populations regardless of ability to pay. Nationwide, nearly 1400 health centre organisations serve over 28 million patients at approximately 12000 service delivery sites. ${ }^{10}$ Clinical quality data are reported annually by health centre organisations as part of their Uniform Data System (UDS) report and are used by HRSA as part of their quality improvement efforts. ${ }^{11}$ Further, incorporating service-area-level community characteristics will help support the ongoing efforts of the federal government to include social risk factors as part of value-based payment reform. ${ }^{12}$

HRSA-funded health centres (henceforth referred to as health centres) are well positioned and are currently working to address social determinants. As health centres serve the most vulnerable patients and their communities, incorporating community-level or service-area-level determinants are just as important as clinical data when evaluating health centre quality outcomes (henceforth referred to as Clinical Quality Measures (CQMs)). To test the impact of social deprivation on health centre performance and clinical outcomes, we created a weighted service area social deprivation score for each health centre and explored clinical performance and quality by service area social deprivation quartile.

\section{METHODS}

All health centres funded under Section 330 of the Public Health Service Act are required to submit annual data through the UDS. The UDS includes organisational and patient characteristics, staffing and utilisation of healthcare services, self-reported urban/rural status, and clinical quality performance. Although a health centre may consist of several service delivery sites, UDS data are aggregated at the 'parent' organisation level. ${ }^{10}$ Health centres report patients by ZIP Codes for every ZIP Code from which at least 11 patients sought services at one or more of their service delivery sites. We used these data to calculate weighted patient-origin service areas, which is based on the ZIP Codes where each of the health centres patients reside. Because population data are available at the ZIP Code Tabulation (ZCTA) level, we used a ZIP Code to ZCTA crosswalk to convert ZIP Codes to ZCTAs. ${ }^{13}$

\section{Creating weighted service area SDI scores}

In 2017, 1373 health centres submitted a UDS report. We removed 213 health centres that did not have complete service area data. The final analysis included 1160 health centres serving more than 22 million mostly low-income patients across the country. We explored CQMs from the UDS by weighted patient-origin service area SDI quartiles for each health centre. The SDI includes a wide variety of measures related to social deprivation including poverty, education, housing, transportation and race. SDI values range from 0 to 100 , and higher values represent higher levels of deprivation. ${ }^{14}$

To create the weighted service area-level SDI score, we first divided the number of patients from each ZCTA going to a health centre by the total number of patients served by the health centre to calculate a weighted percentage for each ZCTA. Next, we multiplied this percentage by the ZCTA SDI score, then summed the adjusted SDI scores for all ZCTAs with health centre patients to calculate a final weighted SDI score (see figure 1). Our final step was to stratify health centres by their service area SDI quartile and explore health centre characteristics and unadjusted and adjusted CQMs by SDI quartile. In addition to exploring health centre patient characteristics by service area social deprivation quartile, we examined health centre characteristics such as enabling services (these include transportation, case management, interpretation services, eligibility assistance and health literacy), patientcentred medical home (PCMH) accreditation status, and total costs per patient (costs of all services including administrative divided total number of patients).

\section{Creating adjusted health centre clinical quality process and outcome measures}

The 2017 UDS included 16 total CQMs, including both process and outcome measures. We performed multiple linear regressions at the health centre level for 12 clinical quality process measures and 3 clinical quality outcome measures (see table 1) to create adjusted measures based on health centre organisational and patient characteristics. We did not include one measure (HIV linkage to care) due to the low number of health centres with complete data. We first removed health centres with missing data. Since data are self-reported and not all health centres provide all services (eg, dental), the number of health centres included for each measure 
ZCTA 1

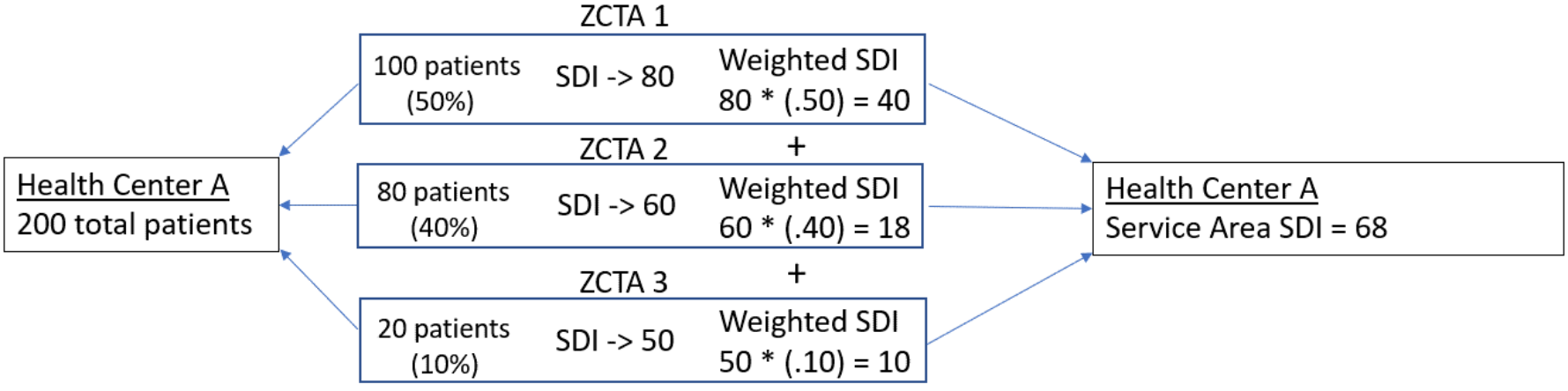

Figure 1 Example of calculating a weighted service area SDI for health centres. SDI, Social Deprivation Index; ZCTA, ZIP code tabulation.

varied from 668 health centres (dental sealants) to 1160 health centres (several measures). Next, we created a correlation matrix to explore the relationship between health centre quality and several health centre characteristics for each of the measures. Several patient characteristic control variables were explored based on previous literature regarding factors affecting health centre performance,${ }^{15-17}$ including veteran status, homelessness, lack of insurance, poverty and low-income rates, patients below age 18 and over age 65 , race and ethnicity and nonEnglish speakers. Potential health centre organisational controls included PCMH accreditation status, EHR system installed and in use by all sites and providers, urban/rural location, and number of health centre patients. Then, we

Table 1 Unadjusted measures by health centre SDI quartile

\begin{tabular}{|c|c|c|c|c|c|c|c|}
\hline & $\begin{array}{l}\text { \# of health } \\
\text { centres }\end{array}$ & $\begin{array}{l}\text { Q1 } \\
\text { (lower social } \\
\text { deprivation }\end{array}$ & Q2 & Q3 & $\begin{array}{l}\text { Q4 } \\
\text { (higher social } \\
\text { deprivation) }\end{array}$ & Overall & Q4-Q1 \\
\hline \multicolumn{8}{|l|}{ Process measures (\%) } \\
\hline $\begin{array}{l}\text { Body mass index screening and } \\
\text { follow-up plan (adults) }\end{array}$ & 1160 & 60.19 & 64.55 & 63.35 & 62.80 & 62.71 & 2.69 \\
\hline Cervical cancer screening & 1160 & 50.63 & 50.39 & 48.72 & 53.36 & 50.75 & $2.73^{*}$ \\
\hline Childhood immunisation status & 994 & 31.53 & 34.83 & 35.95 & 38.29 & 35.15 & $6.76^{\star *}$ \\
\hline Colorectal cancer screening & 1156 & 42.95 & 38.54 & 35.23 & 37.89 & 38.66 & $-5.08^{\star \star}$ \\
\hline Coronary artery disease: lipid therapy & 1009 & 79.98 & 79.82 & 80.41 & 80.68 & 80.21 & 0.70 \\
\hline Dental sealants for children 6-9 years & 668 & 53.11 & 50.51 & 47.89 & 48.97 & 50.12 & $-4.15^{\star}$ \\
\hline Early entry into prenatal care & 796 & 82.95 & 76.99 & 74.14 & 75.19 & 77.32 & $-7.77^{\star \star \star}$ \\
\hline $\begin{array}{l}\text { Ischaemic vascular disease: use of } \\
\text { aspirin or another antiplatelet }\end{array}$ & 1068 & 78.98 & 77.33 & 77.41 & 78.23 & 77.99 & -0.75 \\
\hline $\begin{array}{l}\text { Screening for depression and follow- } \\
\text { up plan }\end{array}$ & 1160 & 65.96 & 66.54 & 65.97 & 63.91 & 65.62 & -2.05 \\
\hline $\begin{array}{l}\text { Tobacco use screening and cessation } \\
\text { intervention }\end{array}$ & 1160 & 88.10 & 87.51 & 84.67 & 85.58 & 86.47 & $-2.52^{\star \star}$ \\
\hline $\begin{array}{l}\text { Use of appropriate medications for } \\
\text { asthma }\end{array}$ & 994 & 84.60 & 84.47 & 85.47 & 85.92 & 85.12 & 1.32 \\
\hline $\begin{array}{l}\text { Weight assessment and counselling } \\
\text { for nutrition and physical activity for } \\
\text { children and adolescents }\end{array}$ & 1120 & 57.81 & 60.78 & 61.45 & 63.48 & 60.84 & $5.63^{\star *}$ \\
\hline \multicolumn{8}{|l|}{ Outcome measures (\%) } \\
\hline $\begin{array}{l}\text { Controlling high blood pressure } \\
(<140 / 90 \mathrm{~mm} \mathrm{Hg})\end{array}$ & 1160 & 65.51 & 62.42 & 60.18 & 60.15 & 62.08 & $-5.36^{\star \star \star x}$ \\
\hline $\begin{array}{l}\text { Diabetes: haemoglobin A1c poor } \\
\text { control }(>9)\end{array}$ & 1154 & 29.90 & 33.04 & 35.61 & 35.29 & 33.45 & $5.38^{\star \star \star}$ \\
\hline Low birth weight (\% of live births) & 1160 & 7.46 & 8.45 & 8.68 & 8.93 & 8.46 & $1.47^{\star \star}$ \\
\hline
\end{tabular}

${ }^{*} \mathrm{P}<0.05,{ }^{* *} \mathrm{p}<0.01,{ }^{* * *} \mathrm{p}<0.001$.

SDI, Social Deprivation Index. 
used backward stepwise regression to determine which variables to keep in the model for each of the measures, focusing on the adjusted r-squared and F-statistic, as well as the multicollinearity index number. Our final model included the control variables that were most consistently included across for all of the measures; these included: percentage of health centre patients who were uninsured, Hispanic, age 65 or older, living in poverty (below $100 \%$ federal poverty guidelines (FPG)) and hypertensive, and categorical variables for PCMH accreditation status and urban/rural location of health centre. In the final step, we performed t-tests for each CQM comparing the health centres in the lowest and highest quartiles for service area social deprivation as we would expect health centres with the highest levels of social deprivation to have poorer clinical quality scores, even after adjusting for organisational and patient characteristics.

\section{RESULTS}

\section{Patient characteristics by SDI quartile}

Table 2 displays health centre patient characteristics by health centre service area SDI quartile, where the highest quartile indicates the highest levels of social deprivation. Patients accessing health centres nested in service areas with the highest social deprivation scores $(\mathrm{Q} 4)$ have higher rates of poverty with $76.8 \%$ of patients at or below $100 \%$ FPG compared with $52.3 \%$ of patients in the lowest SDI quartile (Q1). Compared with Q1, health centre patients in $\mathrm{Q} 4$ are more likely to be a racial or ethnic minority (84.5\% in Q4 and $27.2 \%$ in Q1) and are more likely to be uninsured (24.3\% vs $22.9 \%)$ or on Medicaid $(53.6 \%$ vs $35.9 \%)$. Health centres in higher SDI quartiles have many patients who are homeless (14.2\% in Q4 compared with $3.5 \%$ in Q1), live in public housing $(22.6 \%$ vs $8.8 \%)$, but less likely to be veterans $(0.1 \%$ in $\mathrm{Q} 4$ vs $2.7 \%$ in Q1). Clinically, health centres in $Q 4$ have higher percentages of mental health patients $(10.3 \%$ vs $7.6 \%)$, substance abuse patients $(1.8 \%$ vs $0.6 \%)$. Patients in $\mathrm{Q} 4$ are more likely to use enabling services, which include transportation, case management, interpretation services, eligibility assistance and health literacy $(15.1 \%$ vs $9.9 \%)$, have higher total costs per patient (US\$1160 per patient vs US $\$ 917$ per patient), and are more likely to be in rural areas $(55.1 \%$ vs $20.1 \%$ ).

\section{Adjusted and unadjusted measures by SDI quartile}

Table 1 shows that for 6 of the 12 unadjusted process measures, higher SDI is associated with better health centre performance. These include body mass index (BMI) screening and follow-up plan for adults, cervical cancer screening, childhood immunisation status, lipid therapy, use of appropriate medications for asthma, and weight assessment and counselling for nutrition and physical activity for children and adolescents. Of these, only cervical cancer screening $(53.36 \%$ in Q4 vs $50.63 \%$ in Q1), childhood immunisation status $(38.29 \%$ vs $31.53 \%)$ and weight assessment and counselling for nutrition and physical activity for children and adolescents $(63.48 \%$ vs $57.81 \%$ ) are statistically significant. For the remaining six process measures, higher levels of social deprivation are associated with worse performance. Findings were statistically significant for colorectal cancer screening $(37.89 \%$ in $\mathrm{Q} 4$ vs $42.95 \%$ in Q1), dental sealants for children 6-9 years $(48.97 \%$ vs $53.11 \%)$, early entry into prenatal care $(75.19 \%$ vs $82.95 \%)$ and tobacco use screening and cessation $(85.58 \%$ vs $88.10 \%)$. For all outcome measures, higher levels of social deprivation are associated with statistically significant poorer outcomes in rates of blood pressure control $(60.15 \%$ vs $65.51 \%)$, uncontrolled diabetes $(35.29 \%$ vs $29.90 \%)$, and low birth weight (8.9\% vs $7.46 \%)$.

Table 3 displays the adjusted regression coefficients for each independent variable used to adjust the CQMs. The strongest correlations were between a health centre's percentage of patients over age 65 and rates of colorectal screening (positively correlated) and depression screening (negatively correlated). PCMH certification status was significantly associated with the most measures (11 of 15), all of which indicate PCMH status is associated with better health centre performance. Similarly, a health centre's percentage of Hispanic patients is significantly associated with 10 of 15 measures, with higher percentages of Hispanics associated with better health centre performance. Lower percentages of uninsured patients or patients in poverty are associated with higher health centre performance, significantly for BMI screening, cervical cancer screening, colorectal cancer screening, early entry into prenatal care and controlling high blood pressure.

Table 4 shows that the relationship between service area SDI and CQMs remain mostly unchanged after adjusting for health centre patient and organisation characteristics. The only changes are for depression screening, use of aspirin or another antiplatelet, and dental sealants for children. The adjusted use of aspirin or another antiplatelet measure is significantly higher for health centres with higher social deprivation service areas, while the adjusted dental sealants for children measure is no longer significantly lower in health centres with higher social deprivation service areas. Interestingly, three-quarters of the adjusted clinical quality process measures are better in health centres with higher levels of service area social deprivation, and seven of those measures are statistically significant. The three clinical quality outcome measures are still worse for health centres with the highest service area social deprivation and are statistically significant.

\section{DISCUSSION}

This paper explored the relationship between health centre service area social deprivation, patient characteristics and CQMs. Health centre patient characteristics (table 2) are consistent with the variables included in the SDI. Communities with higher social deprivation scores have a higher proportion of children under the age of 18 
Table 2 Selected health centre patient characteristics by SDI quartile

\begin{tabular}{|c|c|c|c|c|c|}
\hline & $\begin{array}{l}\text { Q1 } \\
\text { (lower social } \\
\text { deprivation) }\end{array}$ & Q2 & Q3 & $\begin{array}{l}\text { Q4 } \\
\text { (higher social } \\
\text { deprivation) }\end{array}$ & $\begin{array}{l}\text { Overall health } \\
\text { centre average }\end{array}$ \\
\hline Average no of patients & 13644 & 21867 & 22018 & 25538 & 20768 \\
\hline \multicolumn{6}{|l|}{ Income } \\
\hline$\%$ Patients below $100 \%$ FPG & 52.3 & 64.1 & 71.3 & 76.8 & 66.1 \\
\hline$\%$ Patients below $200 \%$ FPG & 83.5 & 89.5 & 92.2 & 94.6 & 89.9 \\
\hline \multicolumn{6}{|l|}{ Insurance status } \\
\hline$\%$ Uninsured & 22.9 & 25.4 & 30.0 & 24.3 & 25.7 \\
\hline$\%$ Medicare & 14.1 & 11.5 & 9.7 & 7.8 & 10.8 \\
\hline$\%$ Medicaid patients & 35.9 & 40.2 & 43.9 & 53.6 & 43.5 \\
\hline \multicolumn{6}{|l|}{ Race/ethnicity } \\
\hline \% Patients ethnic/racial minority & 27.2 & 44.2 & 64.3 & 84.5 & 54.5 \\
\hline$\%$ Black & 6.1 & 16.1 & 32.0 & 47.6 & 25.5 \\
\hline$\%$ Asian & 2.3 & 3.2 & 3.6 & 4.5 & 3.4 \\
\hline$\%$ American Indian/Alaskan native & 1.7 & 1.2 & 2.0 & 1.2 & 1.5 \\
\hline \% Hawaiian/Pacific Islander & 1.3 & 0.8 & 1.1 & 0.8 & 1.0 \\
\hline$\%$ Non-Hispanic white & 75.0 & 58.5 & 37.8 & 18.2 & 47.4 \\
\hline \% Hispanic & 15.7 & 22.7 & 27.5 & 37.1 & 25.7 \\
\hline \multicolumn{6}{|l|}{ Age } \\
\hline \% Under age 18 & 25.3 & 27.9 & 26.3 & 28.0 & 26.9 \\
\hline$\%$ Age 65 and older & 13.1 & 10.3 & 8.4 & 7.1 & 9.7 \\
\hline \multicolumn{6}{|l|}{ Special populations } \\
\hline \% Homeless & 3.5 & 4.7 & 8.5 & 14.2 & 7.7 \\
\hline$\%$ Migrant workers & 2.8 & 2.3 & 3.0 & 2.6 & 2.7 \\
\hline$\%$ Veterans & 2.7 & 1.9 & 1.3 & 0.1 & 1.7 \\
\hline \% Public housing & 8.8 & 9.2 & 15.8 & 22.6 & 1.4 \\
\hline \multicolumn{6}{|l|}{ Type of service } \\
\hline$\%$ Medical patients & 80.4 & 83.8 & 83.6 & 84.0 & 83.0 \\
\hline$\%$ Dental patients & 26.4 & 22.9 & 22.0 & 20.2 & 22.9 \\
\hline$\%$ Vision patients & 1.6 & 2.2 & 2.6 & 3.5 & 2.4 \\
\hline$\%$ Mental health patients & 7.6 & 7.7 & 7.9 & 10.3 & 8.4 \\
\hline \% Substance abuse patients & 0.6 & 0.6 & 1.1 & 1.8 & 1.0 \\
\hline$\%$ Enabling services & 9.9 & 8.8 & 12.7 & 15.1 & 11.6 \\
\hline \multicolumn{6}{|l|}{ Other } \\
\hline \% Non-English speaking & 10.7 & 15.5 & 18.5 & 24.0 & 17.2 \\
\hline \% Hypertensive & 28.8 & 29.6 & 30.0 & 26.5 & 28.7 \\
\hline Costs per patients & US\$917 & US $\$ 877$ & US $\$ 932$ & US $\$ 1160$ & US\$971 \\
\hline$\%$ in rural areas & 20.6 & 13.9 & 73.8 & 55.1 & 43.8 \\
\hline \% PCMH accredited & 79.1 & 68.1 & 75.5 & 78.3 & 75.3 \\
\hline
\end{tabular}

FPG, federal poverty guidelines; PCMH, patient-centred medical home; SDI, Social Deprivation Index.

years, and populations more likely to have lower incomes, be uninsured or on Medicaid, and be of racial/ethnic minority. Compared with areas with lower SDI, health centre patients in higher SDI service areas also face social barriers to care including homelessness, living in or immediately adjacent to a public housing site or living in a rural area. Patients in higher SDI areas are also more likely to use enabling services, mental healthcare, and substance use disorder services.

The results of this research also demonstrate the association of service area social deprivation with health centre CQMs, though differences exist between process 
Table 3 Regression coefficients by clinical quality measure

\begin{tabular}{|c|c|c|c|c|c|c|c|}
\hline & \% Hypertensive & PCMH status & $\%$ Uninsured & Urban & \% Poverty & $\% 65+$ & \% Hispanic \\
\hline \multicolumn{8}{|l|}{ Process measures (\%) } \\
\hline $\begin{array}{l}\text { Body mass index } \\
\text { screening and follow- } \\
\text { up plan }\end{array}$ & $0.238^{\star * *}$ & $0.067^{\star \star \star}$ & $0.079^{*}$ & -0.028 & $0.096^{\star *}$ & -0.162 & 0.041 \\
\hline $\begin{array}{l}\text { Cervical cancer } \\
\text { screening }\end{array}$ & 0.062 & $0.058^{*}$ & $-0.091^{\star *}$ & $0.052^{\star \star \star}$ & $-0.105^{\star \star \star}$ & -0.073 & $0.167^{\star \star \star}$ \\
\hline $\begin{array}{l}\text { Colorectal cancer } \\
\text { screening }\end{array}$ & $0.222^{\star \star \star}$ & $0.059^{\star \star \star}$ & $-0.155^{\star \star \star}$ & $0.030^{\star \star}$ & $-0.109^{\star \star \star}$ & $0.524^{\star \star \star}$ & $0.109^{\star \star \star}$ \\
\hline $\begin{array}{l}\text { Coronary artery } \\
\text { disease: lipid therapy }\end{array}$ & 0.069 & $0.023^{\star \star}$ & 0.026 & 0.005 & -0.039 & $-0.160^{\star}$ & 0.028 \\
\hline $\begin{array}{l}\text { Ischaemic vascular } \\
\text { disease: use of } \\
\text { aspirin or another } \\
\text { antiplatelet }\end{array}$ & 0.018 & $0.038^{\star \star \star}$ & -0.026 & $0.024^{\star \star}$ & -0.028 & 0.122 & $0.044^{\star \star *}$ \\
\hline $\begin{array}{l}\text { Screening for } \\
\text { depression and } \\
\text { follow-up plan }\end{array}$ & $0.255^{\star \star}$ & $0.083^{\star \star \star}$ & 0.062 & $-0.034^{\star}$ & -0.048 & $-0.520^{\star \star \star}$ & 0.041 \\
\hline $\begin{array}{l}\text { Tobacco use } \\
\text { screening and } \\
\text { cessation intervention }\end{array}$ & 0.038 & $0.056^{\star \star \star}$ & $-0.043^{*}$ & -0.014 & -0.019 & 0.054 & $0.060^{\star \star \star}$ \\
\hline \multicolumn{8}{|l|}{ Outcome measures (\%) } \\
\hline $\begin{array}{l}\text { Controlling high } \\
\text { blood pressure } \\
(<140 / 90 \mathrm{~mm} \mathrm{Hg})\end{array}$ & 0.001 & $0.013^{*}$ & $-0.121^{\star \star \star}$ & -0.011 & $-0.053^{\star \star}$ & $0.119^{*}$ & $0.058^{\star \star *}$ \\
\hline $\begin{array}{l}\text { Diabetes: } \\
\text { aaemoglobin A1c } \\
\text { poor control }(>9)\end{array}$ & $-0.105^{\star \star}$ & $-0.025^{\star \star}$ & $0.078^{\star \star \star}$ & -0.005 & $0.088^{\star \star \star}$ & $-0.330^{\star \star \star}$ & $-0.025^{\star}$ \\
\hline $\begin{array}{l}\text { Low birth weight (\% } \\
\text { of live births) }\end{array}$ & $0.089^{\star \star \star}$ & -0.000 & $-0.033^{\star \star \star}$ & $0.009^{\star \star}$ & 0.009 & $-0.106^{\star \star}$ & $-0.026^{\star \star *}$ \\
\hline
\end{tabular}

${ }^{*} \mathrm{P}<0.05,{ }^{* *} \mathrm{p}<0.01,{ }^{* *} \mathrm{p}<0.001$.

$\mathrm{PCMH}$, patient-centred medical home.

and outcome measures. Of the 12 clinical quality process measures examined, higher SDI scores were associated with significantly poorer performance with only two of the measures. Two process measures (colorectal cancer screening and early entry to prenatal care) performed worse in areas with higher SDI scores, and two process measures (depression screening and dental sealants) were not statistically significant. These findings are consistent with research on focused on the impact of patient characteristics and enabling services on process measures such as getting a influenza shot and having a routine check-up, indicating that health centres with higher service area social deprivation may follow similar patterns and that enabling services could play a key role in improving care. ${ }^{18}$ More noteworthy, performance in each of the three clinical quality outcome measures (poor diabetes 
Table 4 Adjusted measures by health centre SDI quartile

\begin{tabular}{|c|c|c|c|c|c|c|c|}
\hline & $\begin{array}{l}\text { \# of health } \\
\text { centres }\end{array}$ & $\begin{array}{l}\text { Q1 } \\
\text { (lower social } \\
\text { deprivation }\end{array}$ & Q2 & Q3 & $\begin{array}{l}\text { Q4 } \\
\text { (higher social } \\
\text { deprivation) }\end{array}$ & Overall & Q4-Q1 \\
\hline \multicolumn{8}{|l|}{ Process measures (\%) } \\
\hline $\begin{array}{l}\text { Body mass index screening and } \\
\text { follow-up plan }\end{array}$ & 1160 & 60.73 & 62.66 & 63.74 & 62.77 & 62.48 & $2.04^{\star \star \star}$ \\
\hline Cervical cancer screening & 1160 & 48.99 & 50.56 & 50.89 & 53.31 & 50.75 & $4.32^{\star \star \star}$ \\
\hline Childhood immunisation status & 994 & 35.41 & 36.12 & 37.37 & 41.03 & 37.52 & $5.62^{\star \star \star}$ \\
\hline Colorectal cancer screening & 1156 & 41.83 & 39.33 & 37.32 & 36.82 & 38.83 & $-4.99^{\star \star \star}$ \\
\hline $\begin{array}{l}\text { Coronary artery disease: lipid } \\
\text { therapy }\end{array}$ & 1009 & 80.34 & 80.88 & 81.21 & 81.21 & 80.92 & $0.87^{\star \star \star}$ \\
\hline $\begin{array}{l}\text { Dental sealants for children 6-9 } \\
\text { years }\end{array}$ & 668 & 49.82 & 49.67 & 49.48 & 49.36 & 49.59 & -0.46 \\
\hline Early entry into prenatal care & 796 & 78.60 & 75.79 & 73.26 & 73.29 & 75.00 & $-4.69^{\star \star \star}$ \\
\hline $\begin{array}{l}\text { Ischaemic vascular disease: use } \\
\text { of aspirin or another antiplatelet }\end{array}$ & 1068 & 78.32 & 78.37 & 78.51 & 79.13 & 78.58 & $0.81^{* \star *}$ \\
\hline $\begin{array}{l}\text { Screening for depression and } \\
\text { follow-up plan }\end{array}$ & 1160 & 64.81 & 65.94 & 66.44 & 65.01 & 65.55 & 0.20 \\
\hline $\begin{array}{l}\text { Tobacco use screening and } \\
\text { cessation intervention }\end{array}$ & 1160 & 86.55 & 86.40 & 85.96 & 86.03 & 86.24 & $-0.52^{*}$ \\
\hline $\begin{array}{l}\text { Use of appropriate medications } \\
\text { for asthma }\end{array}$ & 994 & 84.63 & 85.27 & 85.62 & 86.32 & 85 & $1.69^{\star \star \star}$ \\
\hline $\begin{array}{l}\text { Weight assessment and } \\
\text { counselling for nutrition and } \\
\text { physical activity for children and } \\
\text { adolescents }\end{array}$ & 1120 & 57.39 & 60.61 & 62.58 & 64.32 & 61.19 & $6.93^{\star \star \star}$ \\
\hline \multicolumn{8}{|l|}{ Outcome measures (\%) } \\
\hline $\begin{array}{l}\text { Controlling high blood pressure } \\
(<140 / 90 \mathrm{~mm} \mathrm{Hg})\end{array}$ & 1160 & 63.19 & 62.15 & 61.02 & 61.55 & 61.98 & $-1.64^{\star \star \star}$ \\
\hline $\begin{array}{l}\text { Diabetes: haemoglobin A1c poor } \\
\text { control }(>9)\end{array}$ & 1154 & 31.21 & 32.96 & 34.32 & 34.82 & 33.33 & $3.61^{\star \star \star}$ \\
\hline Low birth weight (\% of live births) & 1160 & 8.07 & 8.49 & 8.57 & 8.60 & 8.46 & $0.53^{\star \star}$ \\
\hline
\end{tabular}

${ }^{*} \mathrm{P}<0.05,{ }^{* *} \mathrm{p}<0.01,{ }^{* * *} \mathrm{p}<0.001$.

SDI, Social Deprivation Index.

control, blood pressure control and low birth weight) were all negatively correlated with SDI scores, reinforcing the role social determinants play in health outcomes. ${ }^{19-22}$

Addressing issues related to community social deprivation and improving health centre patient outcomes requires multiple strategies, including cross-agency initiatives that target high-risk populations and patients, and expanded use of health centre enabling services. Providing information to health centre patients about government programmes targeted at low income, pregnant, mental health, substance use disorder or homeless patients could reduce cost, ED utilisation and negative clinical outcomes. ${ }^{23-25}$ For example, low-income patients who used the Supplemental Nutrition Assistance Program (SNAP) expend, on average, US $\$ 1400$ less per year in healthcare costs, ${ }^{23}$ while a state emergency housing assistance programme helped decrease emergency department utilisation for high-risk patients. ${ }^{24}$ In addition, rural patients living within 10 miles of a diabetes management centre were 2.5 times more likely to have improved their haemoglobin A1c values between their first and last visits than those living more than 10 miles away. ${ }^{25}$ Increases in enabling services can directly impact quality, access, and cost of care to reduce social deprivation among safety net populations. ${ }^{18}$ Enabling services provide transportation, case management, interpretation services, eligibility assistance, health literacy and are a major part of the healthcare model. In 2017, two-thirds $(66 \%, \mathrm{n}=911)$ of health centres provided enabling services to patients.

The largest limitation of this analysis is that data are reported for health centres at the network organisation level (ie, parent organisation of all service delivery sites). This limitation was mitigated by calculating weighted SDI scores for health centres (figure 1). Additionally, weighted ZCTA SDI scores only account for patients with known ZIP Codes. While the data collected from health 
centres via the UDS helps incorporate how health centres navigate social barriers (ie, housing and transportation), there are other social constructs that are missing, which encompass neighbourhood characteristics (ie, safety) and more urgent security needs (ie, food). Further, it is not possible to determine if missing data for health centres was not reported or if some health centres did not provide those services. In order to fully comprehend, monitor, and evaluate progress in addressing social determinants' impact on healthcare, it is imperative that health centres have the data needed to define patient complexities and improve population health.

\section{Conclusion}

This paper demonstrates the importance of integrating community-level data into the analysis of health centre CQMs. High levels of social deprivation at the health centre service area level is strongly associated with poorer health centre clinical quality, particularly for the clinical quality outcome measures, where higher levels of social deprivation are associated with poorer diabetes, hypertension, and birth weight outcomes. Potential strategies for mitigating high levels of social deprivation to improve health outcomes are recommended, especially in identifying community factors associated with disparities in access to care and health outcomes.

This research was funded by the US Department of Health and Human Services (HHS), HRSA, under HRSA contract number HHSH2502013000231. The views expressed in this publication are solely the opinions of the authors and do not necessarily reflect the official policies of HHS or HRSA, nor does mention of the department or agency names imply endorsement by the US government. No competing financial or editorial interests were reported by the authors of this paper.

Contributors MT, JM and JR devised the project, carried out the literature review and developed the research question. $\mathrm{HH}$ contributed to literature review, helped to write up the results and contributed to discussion. JB and MT completed the data analysis. AS assisted with writing up the results and discussion. All authors assisted with final review of manuscript.

Funding US Department of Health and Human Services (HHS), Health Resources and Services Administration (HRSA), under HRSA contract number HHSH2502013000231.

Competing interests None declared.

Patient consent for publication Not required.

Ethics approval This research did not require review by an institutional review board (IRB).

Provenance and peer review Not commissioned; externally peer reviewed.

Data availability statement Data for individual Awardess are available from the Health Resources and Services Administration website - https://data.hrsa.gov/tools/ data-reporting/program-data?type=AWARDEE.

Open access This is an open access article distributed in accordance with the Creative Commons Attribution Non Commercial (CC BY-NC 4.0) license, which permits others to distribute, remix, adapt, build upon this work non-commercially, and license their derivative works on different terms, provided the original work is properly cited, appropriate credit is given, any changes made indicated, and the use is non-commercial. See: http://creativecommons.org/licenses/by-nc/4.0/.
REFERENCES

1 National Academies of Sciences, Engineering, and Medicine. Integrating Social Care into the Delivery of Health Care: Moving Upstream to Improve the Nation's Health. Washington, DC: The National Academies Press, 2019.

2 What are social determinants of health? Who.int. Available: https:// www.who.int/social_determinants/sdh_definition/en/ [Accessed 28 Aug 2019].

3 Tarlov AR. Public policy frameworks for improving population health. Ann N Y Acad Sci 1999;896:281-93.

4 Cottrell EK, Gold R, Likumahuwa S, et al. Using health information technology to bring social determinants of health into primary care: a conceptual framework to guide research. $J$ Health Care Poor Underserved 2018;29:949-63.

5 Bazemore AW, Cottrell EK, Gold R, et al. "Community vital signs": incorporating geocoded social determinants into electronic records to promote patient and population health. J Am Med Inform Assoc 2016;23:407-12.

6 Liaw W, Krist AH, Tong ST, et al. Living in "Cold Spot" Communities Is Associated with Poor Health and Health Quality. J Am Board Fam Med 2018;31:342-50.

7 Phillips RL, Liaw W, Crampton P, et al. How other countries use deprivation Indices-And why the United States desperately needs one. Health Aff 2016;35:1991-8.

8 Eibner C, Sturm R. US-based indices of area-level deprivation: results from healthcare for communities. Soc Sci Med 2006;62:348-59.

9 Singh GK. Area deprivation and widening inequalities in US mortality, 1969-1998. Am J Public Health 2003;93:1137-43.

10 Hrsa health center program. Bphc.hrsa.gov, 2018. Available: https:// bphc.hrsa.gov/sites/default/files/bphc/about/healthcenterfactsheet. pdf [Accessed 1 Aug 2019].

11 Hrsa quality improvement. Available: https://bphc.hrsa.gov/ qualityimprovement/clinicalquality/qualityimprovement.html [Accessed 1 Aug 2019].

12 Joynt KE, Zuckerman R, Epstein AM. Social risk factors and performance under Medicare's value-based purchasing programs. Circulation 2017;10:e0033587.

13 Zip code to ZCTA Crosswalk. Udsmapper.org. Available: https:// www.udsmapper.org/zcta-crosswalk.cfm [Accessed 29 Aug 2019].

14 Butler DC, Petterson S, Phillips RL, et al. Measures of social deprivation that predict health care access and need within a rational area of primary care service delivery. Health Serv Res 2013:48:539-59.

15 Chuang E, Pourat N, Chen X, et al. Organizational factors associated with disparities in cervical and colorectal cancer screening rates in community health centers. J Health Care Poor Underserved 2019;30:161-81.

16 et alShin P, Sharac J, Rosenbaum S. Quality of care in community health centers and factors associated with performance. Geiger Gibson/RCHN community health Foundation research collaborative, 2013. Available: https://hsrc.himmelfarb.gwu.edu/sphhs_policy_ ggrchn/45

17 Uniform data system (UDS) health center adjusted Quartile ranking. Bphc.hrsa.gov, 2018. Available: https://bphc.hrsa.gov/datareporting/ reporting/ranking.html [Accessed 28 Aug 2019].

18 Yue D, Pourat N, Chen X, et al. Enabling services improve access to care, preventive services, and satisfaction among health center patients. Health Aff 2019;38:1468-74.

19 Walker RJ, Smalls BL, Campbell JA, et al. Impact of social determinants of health on outcomes for type 2 diabetes: a systematic review. Endocrine 2014;47:29-48.

20 Norton JM, Moxey-Mims MM, Eggers PW, et al. Social determinants of racial disparities in CKD. J Am Soc Nephrol 2016;27:2576-95.

21 Havranek EP, Mujahid MS, Barr DA, et al. Social determinants of risk and outcomes for cardiovascular disease: a scientific statement from the American heart association. Circulation 2015;132:873-98.

22 Adler NE, Glymour MM, Fielding J. Addressing social determinants of health and health inequalities. JAMA 2016;316:1641-2.

23 Berkowitz SA, Seligman HK, Rigdon J, et al. Supplemental nutrition assistance program (SNAP) participation and health care expenditures among low-income adults. JAMA Intern Med 2017;177:1642-9.

24 Clark RE, Weinreb L, Flahive JM, et al. Health care utilization and expenditures of homeless family members before and after emergency housing. Am J Public Health 2018;108:808-14.

25 Zgibor JC, Gieraltowski LB, Talbott EO, et al. The association between driving distance and glycemic control in rural areas. $J$ Diabetes Sci Technol 2011;5:494-500. 
Correction: Exploring the association of social determinants of health and clinical quality measures and performance in HRSA-funded health centres

Topmiller M, McCann J, Rankin J, et al. Exploring the association of social determinants of health and clinical quality measures and performance in HRSA-funded health centres. Fam Med Com Health 2021;9:e000853. doi: 10.1136/fmch-2020-000853

The authors noted an error in the text since the online publication. 'Two process measures (colorectal cancer screening and early entry to prenatal care) performed better in areas with higher SDI scores' has been edited to 'Two process measures (colorectal cancer screening and early entry to prenatal care) performed worse in areas with higher SDI scores.'

Open access This is an open access article distributed in accordance with the Creative Commons Attribution Non Commercial (CC BY-NC 4.0) license, which permits others to distribute, remix, adapt, build upon this work non-commercially, and license their derivative works on different terms, provided the original work is properly cited, appropriate credit is given, any changes made indicated, and the use is non-commercial. See: http://creativecommons.org/licenses/by-nc/4.0/.

( ) Author(s) (or their employer(s)) 2021. Re-use permitted under CC BY-NC. No commercial re-use. See rights and permissions. Published by BMJ.

Fam Med Com Health 2021;9:e000853corr1. doi:10.1136/fmch-2020-000853corr1

Check for updates 